\title{
Quantitative Analysis of Plant Growth Exposed to Electric Fields
}

\author{
Hussein Ahmad', Mohd Hafizi Ahmad ${ }^{\star 2}$, Noor 'Aliaa Awang ${ }^{3}$, Izzah Hazirah Zakaria ${ }^{4}$ \\ ${ }^{1}$ Department of Electrical Power Engineering, Faculty of Electrical and Electronic Engineering, \\ Universiti Tun Hussein Onn Malaysia, Batu Pahat, Johor \\ ${ }^{2,3,4}$ Institute of High Voltage and High Current, Faculty of Electrical Engineering, \\ Universiti Teknologi Malaysia, Skudai, Johor, Malaysia \\ Corresponding author, email: hussein@uthm.edu.my ${ }^{1}$, mohdhafizi@fke.utm.my $^{2}$, \\ noor.aliaa.awang@gmail.com ${ }^{3}$, izzahhazirah13@gmail.com ${ }^{4}$
}

\begin{abstract}
Electromagnetic radiations present in the environment has a profound effect on the growth of vegetable plant primarily grown under the high power transmission lines. The high electric field generated due to ultra high voltage causes the increase and reduction in the size of the plants. Numerous research have been carried out to investigate the effect of electric field on the plants. However, the knowledge in term of quantitative analysis on the effect of electric field on the growth of vegetables is not entirely understood. Thus, this paper presents a study conducted to investigate the effect of high voltage DC electric fields on the young vegetables growth namely 'Choy Sam' and bean sprout. The experimental setup was designed which composed of two parallel plate electrodes. An electric field intensity of $38 \mathrm{kV} / \mathrm{m}$ was suppliedbetween those two plateelectrodes, and it was applied to the young vegetables. This research was focused on the percentage of germination and growing rate of young vegetables. The experiment was divided into two parts. The first part was to test whether there was an effect towards young vegetablesexposed to or not exposed to electric fields. The second part of the experiment was to test the effect of electric fields treated water towards young vegetables. The numbers of seed, temperature and relative humidity were controlled. The changing of vegetables was observedfor 8 hours per day for two weeks (Choy Sam) and one week (bean sprout). The growth of the young vegetables during exposure was calculated by using statistical methods. The analysis of the results showed that the electric fields and the electric fields treated water have influenced the germination rate and height of stems of both young vegetables causing the increase in stem height.
\end{abstract}

Keywords: electromagnetic, electric field, DC high voltage, choy sam, bean sprout

Copyright $\odot 2015$ Institute of Advanced Engineering and Science. All rights reserved.

\section{Introduction}

One of the sources of the electric fields and magnetic fields is the transmission line. In the last few decades, many researches have been performed to observe the effect of electric fields towards the human body and animals. This would probably improve the exposure of the electrical fields, magnetic fields and electromagnetic fields (EMF) for high voltage applications. Conversely, its effect on a human is not just impairments but it also can give more benefits in several approaches if it is well controlled. Since three decades ago, EMF such a various frequency ranges have been used in physiotherapy for the treatment of several diseases.

The recent experimental results of the previous studies indicated that the bean sprout exposed to the vertical electric field direction has a better growth compared to the horizontal part of the electric field direction [1,2]. The investigation was carried out to determine whether by placing the soybean seeds in electric field for a certain period of time would affect their germination rate. If it happens, the period between planting and emergence can be reduced [3]. The initial appearance usually means healthier plants and energy producing higher yields [4]. Therefore, the use of electrical energy to biological organisms has the potential to increase the production of food. This can lead to the uses of electricity to stimulate the growth of the fair organism or use it to slow down the growth or reproduction of unwanted organisms. If either of these approaches yields positive results, humans would benefit [4]. The effect of electric field 
treated water towards young vegetables whichwere a new kind of method has been carried out to give more significant results.

Furthermore, Mahajan and Pandey [5] investigated the effect of the electric field with varying voltage on the absorption of water and germination of soybean seed. The study was conducted to find the resonant electric field that has a significant effect on the proliferation and the growth of soybean seed. It was found that seedlings were sensitive to some specific value of magnetic field.

Since there were numerous studies on the effect of electric field, magnetic field and electromagnetic field on human, animal and plants but the quantitative analysis of the effect of electric field on plants is still lacking and not fully understood. The quantitative measure of plant changes towards exposed electric field would give more definitive understanding rather than subjective comparison.

Thus, in this study, we focused on the effect of DC electric field on the growth of young vegetables namely 'Choy Sam' and bean sprout. Bean sproutwas chosen due to its simplicity and very fast growth rate. Also, the statistical analysis was performed to yield more quantitative and definitive understanding towards the effect of the electric field as well as definitive comparison.

\section{Experimental Setup}

For the first part of the experiment, the seed of young vegetables were planted in a few plastic boxes at the room temperature. Three implemental boxes were used, and three are a total of 50 seeds of 'Choy Sam' were planted in the boxes. Special black soils were mixed with red soils with the ratio 3:2 were used for plant growing where the amount of water was controlled. Apart from that, an implemental box was used, and total 40 seeds of bean sprout were planted in the box. Cotton-wool was used for bean sprout growing where the amount of water is controlled. Then, these boxes of seeds are put under exposure to electric fields. The same amount of seeds, boxes, soils and cotton-wool were prepared as a reference. The comparison of plant growing between with and without electric field was done. This research focused on the percentage of germination and the height of stems. Temperature and relative humidity were controlled. The room temperature was about $32{ }^{\circ} \mathrm{C}$. A $38 \mathrm{kV}$ DC voltage was applied to obtain electric field intensity of $38 \mathrm{kV} / \mathrm{m}$.

For the second part of the experiment, the preparation for the seeds of 'Choy Sam' and bean sprout, boxes, soils and cotton-wool were similar to the first part of the research. The reference set of seeds that used in the first experiment was used as a reference set in this experiment. The comparison of plant growing between with and without electric fields treated water was done. This research focused on the percentage of germination and the height of stems. Temperature and relative humidity were controlled and similar to the first experiment. A $38 \mathrm{kV}$ DC Voltage was applied to obtain electric field intensity of $38 \mathrm{kV} / \mathrm{m}$. Firstly, the main supply was attached to variac. The function of variac was to adjust the input voltage. Then, the variac was connected to HV transformer that was used to step-up the input voltage. After that, the HV transformer was attached to the rectifier. The diodes in rectifier were used to convert AC to DCsupply, and the capacitor was used to smooth the ripple voltage. The low voltage amp was used to reduce the voltage to a particular value and then only be connected to a digital multimeter. From the rectifier, it was then attached to the two-plate electrodes. The upper aluminium plate (anode) was connected to the cable between the rectifier and the lower aluminium plate (cathode) was connected to earth. The distance between these two aluminium plates was $1 \mathrm{~m}$. The cable from the rectifierwas attached from the top to the anode and supported by bushing so that the direction of electric fields was fromupper plate to lower. There were no sharp edges at the four corners of upper aluminium plate and four metal balls were screwed at the four corners to reduce the effect of corona when high voltage was supplied to the upper plate [6].

\section{Experimental Results}

\subsection{Comparison between the Percentage of Germination and Growing Rate of Plants with and without Electric Fields}

TELKOMNIKA Vol. 16, No. 2, November 2015 : 207 - 220 
Firstly, the percentages of germination and growth rate of 'Choy Sam' were observed. For the percentage of germination, the result is shown in Table 1.

For the growth rate, the statistical methods were used [7, 8]. The result of hypothesis test involving differences of two population means, $\mu_{1}-\mu_{2}\left(n_{1} \geq 30, n_{2} \geq 30\right)$ is shown in Table 2. The 30 height plants were chosen in this method. The analysis conditions of the collected data are as follows,

1. $n_{1}=n_{2}=30$

2. Significance level $=\alpha=5 \%$

3. Null hypothesis is $\mathrm{H}_{\mathrm{O}}: \mu_{1}=\mu_{2}$

4. Alternative hypothesis is $\mathrm{H}_{1}: \mu_{1}>\mu_{2}$

5. Reject $\mathrm{H}_{\mathrm{O}}$ if $\mathrm{Z}_{\text {test }}>\mathrm{Z}_{\mathrm{\alpha}}=\mathrm{Z}_{0.05}=1.6449$

Table 1. The percentage of germination for 'Choy Sam' which exposed to electric fields and non-electric fields

\begin{tabular}{ccc}
\hline Time & $\begin{array}{c}\text { Percentage of germination with } \\
\text { electric fields (\%) }\end{array}$ & $\begin{array}{c}\text { Percentage of germination without } \\
\text { electric fields (\%) }\end{array}$ \\
Day 1 & 0 & 0 \\
Day 2 & 34 & 14 \\
Day 3 & 74 & 72 \\
Day 4 & 74 & 74 \\
Day 5 & 76 & 74 \\
Day 6 & 76 & 74 \\
Day 7 & 76 & 74 \\
Day 8 & 76 & 74 \\
Day 9 & 76 & 74 \\
Day 10 & 76 & 74 \\
Day 11 & 76 & 74 \\
Day 12 & 76 & 74 \\
Day 13 & 76 & 74 \\
Day 14 & 76 & 74 \\
\hline
\end{tabular}

Table 2. Mean, standard deviation and Z-value of the height of stem

\begin{tabular}{|c|c|c|c|c|c|c|}
\hline \multirow{2}{*}{ Time } & \multicolumn{2}{|c|}{ Mean(mm) } & \multicolumn{2}{|c|}{ StandardDeviation(mm) } & \multirow{2}{*}{$\begin{array}{c}\mathrm{Z}_{\text {test }} \\
\text { Value }\end{array}$} & \multirow{2}{*}{ Result } \\
\hline & E-fields & Non E-fields & E-fields & Non E-fields & & \\
\hline Day 1 & 0 & 0 & 0 & 0 & 0 & $\mu_{1}=\mu_{2}$ \\
\hline Day 2 & 1.33 & 0.30 & 1.49 & 0.59 & 3.52 & $\mu_{1}>\mu_{2}$ \\
\hline Day 3 & 9.93 & 8.23 & 3.12 & 1.77 & 2.58 & $\mu_{1}>\mu_{2}$ \\
\hline Day 4 & 38.56 & 38.66 & 4.52 & 2.78 & -0.10 & $\mu_{1}=\mu_{2}$ \\
\hline Day 5 & 58.66 & 57.90 & 5.66 & 4.12 & 0.59 & $\mu_{1}=\mu_{2}$ \\
\hline Day 6 & 73.53 & 73.36 & 6.54 & 5.35 & 0.10 & $\mu_{1}=\mu_{2}$ \\
\hline Day 7 & 78.90 & 78.73 & 7.59 & 6.85 & 0.09 & $\mu_{1}=\mu_{2}$ \\
\hline Day 8 & 83.20 & 81.83 & 8.08 & 7.57 & 0.68 & $\mu_{1}=\mu_{2}$ \\
\hline Day 9 & 85.03 & 83.20 & 7.77 & 8.19 & 0.89 & $\mu_{1}=\mu_{2}$ \\
\hline Day 10 & 86.43 & 84.06 & 7.95 & 7.91 & 1.15 & $\mu_{1}=\mu_{2}$ \\
\hline Day 11 & 87.10 & 84.70 & 8.13 & 8.37 & 1.13 & $\mu_{1}=\mu_{2}$ \\
\hline Day 12 & 87.83 & 84.96 & 8.14 & 8.38 & 1.34 & $\mu_{1}=\mu_{2}$ \\
\hline Day 13 & 88.10 & 84.96 & 8.05 & 8.38 & 1.48 & $\mu_{1}=\mu_{2}$ \\
\hline Day 14 & 88.13 & 85.43 & 8.02 & 8.64 & 1.25 & $\mu_{1}=\mu_{2}$ \\
\hline
\end{tabular}

Table 3. The result of F-test in ANOVA

\begin{tabular}{ccc}
\hline Time & $\boldsymbol{f}$ Value & Result \\
\hline Day 1 & 0 & No treatment effect \\
Day 2 & 12.3905 & Positive treatment effect \\
Day 3 & 6.7000 & Positive treatment effect \\
Day 4 & 0.0106 & No treatment effect \\
Day 5 & 0.3593 & No treatment effect \\
\hline
\end{tabular}




\begin{tabular}{ccc}
\hline Day 6 & 0.0116 & No treatment effect \\
Day 7 & 0.0080 & No treatment effect \\
Day 8 & 0.4563 & No treatment effect \\
Day 9 & 0.7903 & No treatment effect \\
Day 10 & 1.3338 & No treatment effect \\
Day 11 & 1.2677 & No treatment effect \\
Day 12 & 1.8048 & No treatment effect \\
Day 13 & 2.1803 & No treatment effect \\
Day 14 & 1.5718 & No treatment effect
\end{tabular}

The result of F-test in ANOVA is shown in Table 3. 30 highest plants were chosen in this method. The analysis conditions of the collected data are listed as follows;

1. $n_{i}=n_{k}=30$

2. $\mathrm{N}=60, \mathrm{k}=2$

3. Significance level $=\alpha=5 \%$

4. $\mathrm{H}_{0}: \alpha_{1}=\alpha_{2}=0$ Versus $H_{1}: \alpha_{i} \neq 0$

5. Reject $\mathrm{H}_{O}$ if $f$ value $>f_{\alpha ; k-1, N-k}=f_{0.05 ; 1,58}=4.00$

Where $\alpha_{i}$ is the $\mathrm{i}$-th treatment effect.

The results of independence tests are shown in Table 4 and Table 5. The analysis conditions of the collected data are listed as follows,

1. Significance level $=\alpha=5 \%$

2. $H_{\mathrm{O}}$ : the height of 'Choy Sam' and exposed/do not expose to electric fields are independent

3. $\mathrm{H}_{1}$ : the height of 'Choy Sam' and exposed/do not expose to electric fields are dependent

4. Reject $\mathrm{H}_{\mathrm{O}}$ if $X^{2}>X_{\alpha,(r-1)(c-1)}^{2}=X_{0.005,1}^{2}=3.841$

Table 4. The number of plants that the heights of stem are less than $90 \mathrm{~mm}$ or exceeding $90 \mathrm{~mm}$

\begin{tabular}{lcc}
\hline \multicolumn{1}{c}{ Conditions } & \multicolumn{2}{c}{ Height of stems } \\
& $<\mathbf{9 0} \mathbf{~ m m}$ & $\geq \mathbf{9 0} \mathbf{~ m m}$ \\
\hline Exposed to electric fields & 36 & 14 \\
Do not expose to electric fields & 40 & 10 \\
\hline
\end{tabular}

Table 5. The value of $O_{i j}, E_{i j}, X^{2}$.

\begin{tabular}{ccc}
\hline \multirow{2}{*}{$\boldsymbol{o}_{i j}$} & $\boldsymbol{E}_{\boldsymbol{i j}}$ & $\frac{\left(\boldsymbol{o}_{i j}-\boldsymbol{E}_{\boldsymbol{i j}}\right)^{\mathbf{2}}}{\boldsymbol{E}_{\boldsymbol{i j}}}$ \\
\hline 36 & 38.0000 & 0.1053 \\
14 & 12.0000 & 0.3333 \\
40 & 38.0000 & 0.1053 \\
10 & 12.0000 & 0.3333 \\
& $X^{2}$ & 0.8772 \\
\hline
\end{tabular}

Since $X^{2}<3.841$, thus we accept $H_{O}$ and conclude that the height of stems is independent on exposed/do not exposed to electric fields.

Secondly, the percentage of germination and growth rate of bean sprout were observed. For the percentage of germination, the result is shown in Table 6.

Table 6. The percentage of germination for bean sprouts that exposed to electric fields and non-electric fields

\begin{tabular}{ccc}
\hline Time & $\begin{array}{c}\text { Percentage of germination with electric } \\
\text { fields (\%) }\end{array}$ & $\begin{array}{c}\text { Percentage of germination without } \\
\text { electric fields (\%) }\end{array}$ \\
\hline Day 1 & 0 & 0 \\
Day 2 & 82.5 & 65.0 \\
\hline
\end{tabular}

TELKOMNIKA Vol. 16, No. 2, November 2015 : 207 - 220 


\begin{tabular}{lll}
\hline Day 3 & 95.0 & 90.0 \\
Day 4 & 95.0 & 90.0 \\
Day 5 & 95.0 & 90.0 \\
Day 6 & 95.0 & 90.0 \\
\hline
\end{tabular}

For the growth rate, the result of hypothesis test involving differences of two population means, $\mu_{1}-\mu_{2}\left(n_{1}<30, n_{2}<30\right)$ is shown as Table 7. 20 highest plants are chosen in this method. The analysis conditions of the collected data are as follows;

1. $n_{1}=n_{2}=20$

2. Significance level $=\alpha=5 \%$

3. Null hypothesis is $\mathrm{H}_{\mathrm{O}}: \mu_{1}=\mu_{2}$

4. Alternative hypothesis is $\mathrm{H}_{1}: \mu_{1}>\mu_{2}$

5. Reject $\mathrm{H}_{\mathrm{O}}$ if $\mathrm{t}_{\text {test }}>\mathrm{t}_{\alpha, \mathrm{v}} \approx 1$.

Table 7. Mean, standard deviation and t-value of the height of the stem.

\begin{tabular}{ccccccc} 
Time & \multicolumn{2}{c}{ Mean(mm) } & \multicolumn{2}{c}{ StandardDeviation(mm) } & $\begin{array}{c}\mathbf{t}_{\text {test }} \\
\text { Value }\end{array}$ & Result \\
& E-fields & Non E-fields & E-fields & Non E-fields & & \\
\hline Day 1 & 0 & 0 & 0 & 0 & 0 & $\mu_{1}=\mu_{2}$ \\
Day 2 & 3.90 & 1.40 & 1.02 & 0.59 & 9.44 & $\mu_{1}>\mu_{2}$ \\
Day 3 & 7.80 & 4.45 & 2.35 & 1.31 & 5.55 & $\mu_{1}>\mu_{2}$ \\
Day 4 & 23.75 & 16.40 & 10.48 & 7.01 & 2.60 & $\mu_{1}>\mu_{2}$ \\
Day 5 & 87.70 & 62.05 & 24.40 & 29.63 & 2.98 & $\mu_{1}>\mu_{2}$ \\
Day 6 & 113.10 & 84.40 & 25.24 & 33.89 & 3.03 & $\mu_{1}>\mu_{2}$ \\
\hline
\end{tabular}

The result of F-test in ANOVA is shown in Table 8. The 20 highest plants were chosen in this method. The analysis conditions of the collected data are listed as follows,

1. $n_{i}=n_{k}=20$

2. $\mathrm{N}=40, \mathrm{k}=2$

3. Significance level $=\alpha=5 \%$

4. $\mathrm{H}_{0}: \alpha_{1}=\alpha_{2}=0$ Versus $H_{1}: \alpha_{i} \neq 0$

5. Reject $\mathrm{H}_{O}$ if $f$ value $>f_{\alpha ; k-1, N-k}=f_{0.05 ; 1,38}=4.1247$

Where $\alpha_{i}$ is the $i$-th treatment effect.

\begin{tabular}{ccc}
\multicolumn{3}{c}{ Table 8. The result of F-test in ANOVA } \\
\hline Time & $\boldsymbol{f}$ Value & \multicolumn{1}{c}{ Result } \\
\hline Day 1 & 0 & No treatment effect \\
Day 2 & 89.2857 & Positive treatment effect \\
Day 3 & 30.8690 & Positive treatment effect \\
Day 4 & 6.7873 & Positive treatment effect \\
Day 5 & 8.9279 & Positive treatment effect \\
Day 6 & 9.2253 & Positive treatment effect \\
\hline
\end{tabular}

The results of independence testsare shown in Table 9 and Table 10. The analysis conditions of the collected data are as follows;

1. Significance level $=\alpha=5 \%$

2. $\mathrm{H}_{\mathrm{O}}$ : the height of bean sprout and exposed/do not expose to electric fields are independent

3. $\mathrm{H}_{1}$ : the height of bean sprout and exposed/do not expose to electric fields are dependent

4. Reject $\mathrm{H}_{\mathrm{O}}$ if $X^{2}>X_{\alpha,(r-1)(c-1)}^{2}=X_{0.005,1}^{2}=3.841$. 
Table 9. The number of plants that the heights of stem are less than $100 \mathrm{~mm}$ or exceeding

\begin{tabular}{lcc}
\multicolumn{3}{c}{$100 \mathrm{~mm}$} \\
\hline \multicolumn{1}{c}{ Conditions } & \multicolumn{2}{c}{ Height of stems } \\
& $<\mathbf{1 0 0} \mathbf{~ m m}$ & $\geq \mathbf{1 0 0} \mathbf{~ m m}$ \\
\hline Exposed to electric fields & 22 & 18 \\
Do not expose to electric fields & 33 & 7 \\
\hline
\end{tabular}

Table 10. The value of $O_{i j}, E_{i j}, X^{2}$
\begin{tabular}{ccc}
\hline $\boldsymbol{o}_{i j}$ & $\boldsymbol{E}_{\boldsymbol{i} j}$ & $\frac{\left(\boldsymbol{o}_{i j}-\boldsymbol{E}_{\boldsymbol{i j}}\right)^{2}}{\boldsymbol{E}_{\boldsymbol{i j}}}$ \\
\hline 22 & 27.5000 & 1.1000 \\
18 & 12.5000 & 2.4200 \\
33 & 27.5000 & 1.1000 \\
7 & 12.5000 & 2.4200 \\
& $X^{2}$ & 7.0400 \\
\hline
\end{tabular}

Since $X^{2}>3.841$, so we reject $H_{O}$ and conclude that the height of stems is dependent on exposed/do not exposed to electric fields.

\subsection{Comparison between the Percentage of Germination and Growth Rate of Plants that Watered with and without Electric Fields Treated Water}

Firstly, the percentage of germination and growth rate of 'Choy Sam' were observed. For the percentage of germination, the result is shown in Table 11.

Table 11. The percentage of germination for 'Choy Sam' which watered with and without electric fields treated water

\begin{tabular}{ccc}
\hline Time & $\begin{array}{c}\text { Percentage of germination with } \\
\text { electric fields (\%) }\end{array}$ & $\begin{array}{c}\text { Percentage of germination } \\
\text { without electric fields (\%) }\end{array}$ \\
\hline Day 1 & 0 & 0 \\
Day 2 & 16 & 14 \\
Day 3 & 68 & 72 \\
Day 4 & 68 & 74 \\
Day 5 & 68 & 74 \\
Day 6 & 70 & 74 \\
Day 7 & 70 & 74 \\
Day 8 & 70 & 74 \\
Day 9 & 70 & 74 \\
Day 10 & 70 & 74 \\
Day 11 & 70 & 74 \\
Day 12 & 70 & 74 \\
Day 13 & 70 & 74 \\
Day 14 & 70 & 74 \\
\hline
\end{tabular}

Table 12. Mean, standard deviation and Z-value of the height of stem

\begin{tabular}{ccccccc}
\hline \multirow{2}{*}{ Time } & \multicolumn{2}{c}{ Mean(mm) } & \multicolumn{2}{c}{ StandardDeviation(mm) } & \multirow{2}{*}{$\begin{array}{c}\text { Z } \\
\text { test }\end{array}$} & Result \\
& E-fields & Non E-fields & E-fields & Non E-fields & Value & \\
\hline Day 1 & 0 & 0 & 0 & 0 & 0 & $\mu_{1}=\mu_{2}$ \\
Day 2 & 0.66 & 0.30 & 1.29 & 0.59 & 1.40 & $\mu_{1}=\mu_{2}$ \\
Day 3 & 7.03 & 8.2333 & 3.63 & 1.77 & -1.62 & $\mu_{1}=\mu_{2}$ \\
Day 4 & 35.96 & 38.66 & 3.39 & 2.78 & -3.36 & $\mu_{1}=\mu_{2}$ \\
Day 5 & 56.60 & 57.90 & 5.59 & 4.12 & -1.02 & $\mu_{1}=\mu_{2}$ \\
Day 6 & 72.36 & 73.36 & 8.16 & 5.35 & -0.56 & $\mu_{1}=\mu_{2}$ \\
Day 7 & 80.23 & 78.73 & 7.53 & 6.85 & 0.80 & $\mu_{1}=\mu_{2}$ \\
Dav 8 & 84.90 & 81.83 & 7.80 & 7.57 & 1.54 & $\mu_{1}=u_{2}$ \\
\hline
\end{tabular}

TELKOMNIKA Vol. 16, No. 2, November 2015: $207-220$ 


\begin{tabular}{ccccccc}
\hline Day 9 & 87.26 & 83.20 & 7.43 & 8.19 & 2.01 & $\mu_{1}>\mu_{2}$ \\
Day 10 & 88.33 & 84.06 & 7.72 & 7.91 & 2.11 & $\mu_{1}>\mu_{2}$ \\
Day 11 & 89.73 & 84.70 & 7.66 & 8.37 & 2.42 & $\mu_{1}>\mu_{2}$ \\
Day 12 & 90.36 & 84.96 & 7.56 & 8.38 & 2.62 & $\mu_{1}>\mu_{2}$ \\
Day 13 & 90.80 & 84.96 & 7.60 & 8.38 & 2.82 & $\mu_{1}>\mu_{2}$ \\
Day 14 & 90.80 & 85.43 & 7.60 & 8.64 & 2.55 & $\mu_{1}>\mu_{2}$ \\
\hline
\end{tabular}

For the growth rate, the result of hypothesis test involving differences of two population means, $\mu_{1}-\mu_{2}\left(n_{1} \geq 30, n_{2} \geq 30\right)$ is shown in Table 12. The 30 height plants were chosen in this method. The analysis conditions of the collected data are as follows,

1. $n_{1}=n_{2}=30$

2. Significance level $=\alpha=5 \%$

3. Null hypothesis is $\mathrm{H}_{\mathrm{O}}: \mu_{1}=\mu_{2}$

4. Alternative hypothesis is $\mathrm{H}_{1}: \mu_{1}>\mu_{2}$

Reject $\mathrm{H}_{\mathrm{O}}$ if $\mathrm{Z}_{\text {test }}>\mathrm{Z}_{\alpha}=\mathrm{Z}_{0.05}=1.6449$.

The result of F-test in ANOVA is shown as Table 13. The 30 highest plants were chosen in this method. The analysis conditions of the collected data as follows;

1. $n_{i}=n_{k}=30$

2. $\mathrm{N}=60, \mathrm{k}=2$

3. Significance level $=\alpha=5 \%$

4. $\mathrm{H}_{0}: \alpha_{1}=\alpha_{2}=0$ Versus $H_{1}: \alpha_{i} \neq 0$

5. Reject $\mathrm{H}_{O}$ if $f$ value $>f_{\alpha ; k-1, N-k}=f_{0.05 ; 1,58}=4.00$.

Where $\alpha_{i}$ is the $i$-th treatment effect.

\begin{tabular}{ccc}
\multicolumn{3}{c}{ Table 13. The Result of F-test in ANOVA } \\
\hline Time & $\boldsymbol{f}$ Value & Result \\
\hline Day 1 & 0 & No treatment effect \\
Day 2 & 1.9841 & No treatment effect \\
Day 3 & 2.6410 & No treatment effect \\
Day 4 & 11.3360 & Adverse treatment effect \\
Day 5 & 1.0488 & No treatment effect \\
Day 6 & 0.3148 & No treatment effect \\
Day 7 & 0.6500 & No treatment effect \\
Day 8 & 2.3833 & No treatment effect \\
Day 9 & 4.0501 & Adverse treatment effect \\
Day 10 & 4.4606 & Positive treatment effect \\
Day 11 & 5.8927 & Positive treatment effect \\
Day 12 & 6.8647 & Positive treatment effect \\
Day 13 & 7.9675 & Positive treatment effect \\
Day 14 & 6.5146 & Positive treatment effect \\
\hline
\end{tabular}

Negative treatment effect happened because of the average height of 'Choy Sam' which watered by electric fields treated water are lower than without electric fields treated water.

The result of independence test is shownin table 14 and table 15. The analysis conditions of the collected data are as follows,

1. Significance level $=\alpha=5 \%$

2. $\mathrm{H}_{\mathrm{O}}$ : the height of 'Choy Sam' and watered with/without electric fields treated water are independent

3. $\mathrm{H}_{1}$ : the height of 'Choy Sam' and watered with/without electric fields treated water are dependent

4. Reject $\mathrm{H}_{\mathrm{O}}$ if $X^{2}>X_{\alpha,(r-1)(c-1)}^{2}=X_{0.005,1}^{2}=3.841$

Table 14. The number of plants that the heights of stem are less than $90 \mathrm{~mm}$ or exceeding $90 \mathrm{~mm}$

\begin{tabular}{ccc}
\hline Condition & \multicolumn{2}{c}{ Height of stems } \\
& $<90 \mathbf{~ m m}$ & $\geq \mathbf{9 0} \mathbf{~ m m}$ \\
\hline Exposed to electric fields & 31 & 19 \\
\hline
\end{tabular}




\begin{tabular}{|c|c|c|}
\hline \multicolumn{3}{|c|}{ Do not expose to electric fields } \\
\hline \multicolumn{3}{|c|}{ Table 15. The value of $O_{i j}, E_{i j}, X^{2}$} \\
\hline $\boldsymbol{O}_{i j}$ & $E_{i j}$ & $\frac{\left(o_{i j}-E_{i j}\right)^{2}}{E_{i j}}$ \\
\hline 31 & 35.5000 & 0.5704 \\
\hline 19 & 14.5000 & 1.3966 \\
\hline 40 & 35.5000 & 0.5704 \\
\hline 10 & 14.5000 & 1.3966 \\
\hline & $X^{2}$ & 3.9340 \\
\hline
\end{tabular}

Since $X^{2}>3.841$, so we reject $H_{O}$ and conclude that the height of stems is dependent on watered with/without electric fields treated water.

Secondly, the percentage of germination and growth rate of bean sprout are observed. For the percentage of germination, the result is shown in Table 16.

Table 16. The percentage of germination for bean sprouts that watered with/without electric fields treated water

\begin{tabular}{ccc}
\hline Time & $\begin{array}{c}\text { Percentage of germination with electric } \\
\text { fields (\%) }\end{array}$ & $\begin{array}{c}\text { Percentage of germination without } \\
\text { electric fields (\%) }\end{array}$ \\
\hline Day 1 & 0 & 0 \\
Day 2 & 75 & 65.0 \\
Day 3 & 92.5 & 90.0 \\
Day 4 & 92.5 & 90.0 \\
Day 5 & 92.5 & 90.0 \\
Day 6 & 92.5 & 90.0 \\
\hline
\end{tabular}

For the growth rate, the result of hypothesis test involving differences of two population means, $\mu_{1}-\mu_{2}\left(n_{1}<30, n_{2}<30\right)$ is shown as table 17. 20 highest plants were chosen in this method.

The analysis conditions of the collected data are as follows,

1. $n_{1}=n_{2}=20$

2. Significance level $=\alpha=5 \%$

3. Null hypothesis is $\mathrm{H}_{\mathrm{O}}: \mu_{1}=\mu_{2}$

4. Alternative hypothesis is $\mathrm{H}_{1}: \mu_{1}>\mu_{2}$

5. Reject $\mathrm{H}_{\mathrm{O}}$ if $\mathrm{t}_{\text {test }}>\mathrm{t}_{\alpha, \mathrm{v}} \approx 1.69$

Table 17. Mean, standard deviation and t-value of the height of the stem

\begin{tabular}{ccccccc}
\hline \multirow{2}{*}{ Time } & \multicolumn{2}{c}{ Mean(mm) } & \multicolumn{2}{c}{ StandardDeviation(mm) } & \multirow{2}{\mathbf{t}_{\text{test}}}{ Result } \\
& E-fields & Non E-fields & E-fields & Non E-fields & Value & \\
\hline Day 1 & 0 & 0 & 0 & 0 & 0 & $\mu_{1}=\mu_{2}$ \\
Day 2 & 2.25 & 1.40 & 0.63 & 0.59 & 4.43 & $\mu_{1}>\mu_{2}$ \\
Day 3 & 5.70 & 4.45 & 1.58 & 1.31 & 2.82 & $\mu_{1}>\mu_{2}$ \\
Day 4 & 19.05 & 16.40 & 6.42 & 7.01 & 1.24 & $\mu_{1}=\mu_{2}$ \\
Day 5 & 79.05 & 62.05 & 26.14 & 29.63 & 1.92 & $\mu_{1}>\mu_{2}$ \\
Day 6 & 100.5 & 84.40 & 25.11 & 33.89 & 1.70 & $\mu_{1}>\mu_{2}$ \\
\hline
\end{tabular}

The result of F-test in ANOVA is shown in Table 18. 20 highest plants were chosen in this method. The analysis conditions of the collected data are as follows,

1. $n_{i}=n_{k}=20$

2. $\mathrm{N}=40, \mathrm{k}=2$

3. Significance level $=\alpha=5 \%$

4. $\mathrm{H}_{O}: \alpha_{1}=\alpha_{2}=0$ Versus $H_{1}: \alpha_{i} \neq 0$

5. Reject $\mathrm{H}_{O}$ if $f$ value $>f_{\alpha ; k-1, N-k}=f_{0.05 ; 1,38}=4.1247$

Where $\alpha_{i}$ is the $i$-th treatment effect.

TELKOMNIKA Vol. 16, No. 2, November 2015 : 207 - 220 


\begin{tabular}{ccc}
\multicolumn{3}{c}{ Table 18. The result of F-test in ANOVA } \\
\hline Time & $\boldsymbol{f}$ Value & Result \\
\hline Day 1 & 0 & No treatment effect \\
Day 2 & 18.8694 & Positive treatment effect \\
Day 3 & 7.9579 & Positive treatment effect \\
Day 4 & 1.5517 & No treatment effect \\
Day 5 & 3.70065 & No treatment effect \\
Day 6 & 2.9132 & No treatment effect \\
\hline
\end{tabular}

The result of independence test is shownin Table 19 and Table 20. The analysis conditions of the collected data are as follows;

1. Significance level $=\alpha=5 \%$

2. $\mathrm{H}_{\mathrm{O}}$ : the height of bean sprout and watered with/without electric fields treated water are independent

3. $\mathrm{H}_{1}$ : the height of bean sprout and watered with/without electric fields treated water are independent

4. Reject $\mathrm{H}_{\mathrm{O}}$ if $X^{2}>X_{\alpha,(r-1)(c-1)}^{2}=X_{0.005,1}^{2}=3.841$.

Table 19. The number of plants that the heights of stem are less than $100 \mathrm{~mm}$ or exceeding

\begin{tabular}{lcc}
\multicolumn{3}{c}{$100 \mathrm{~mm}$} \\
\multicolumn{1}{c}{ Condition } & \multicolumn{2}{c}{ Height of stems } \\
& $<\mathbf{1 0 0 ~} \mathbf{~ m m}$ & $\geq \mathbf{1 0 0} \mathbf{~ m m}$ \\
\hline Exposed to electric fields & 28 & 12 \\
Do not expose to electric fields & 33 & 7 \\
\hline
\end{tabular}

Table 20. The value of $O_{i j}, E_{i j}, X^{2}$

\begin{tabular}{ccc}
\hline $\boldsymbol{O}_{i j}$ & $\boldsymbol{E}_{i j}$ & $\frac{\left(\boldsymbol{O}_{i j}-\boldsymbol{E}_{i j}\right)^{2}}{\boldsymbol{E}_{i j}}$ \\
\hline 28 & 30.5000 & 0.2049 \\
12 & 9.5000 & 0.6579 \\
33 & 30.5000 & 0.2049 \\
7 & 9.5000 & 0.6579 \\
& $X^{2}$ & 1.7256 \\
\hline
\end{tabular}

Since $X^{2}<3.841$, so we accept $H_{O}$ and conclude that the height of stems is independent on watered with/without electric fields treated water.

\section{Analysis}

Figure 1 and 2 show the comparison between the height of stem of 'Choy Sam' and bean sprouts with and without electric fields respectively. The heights of the stem for both young vegetables thatare exposed to electric fields are higher than those without electric fields. 


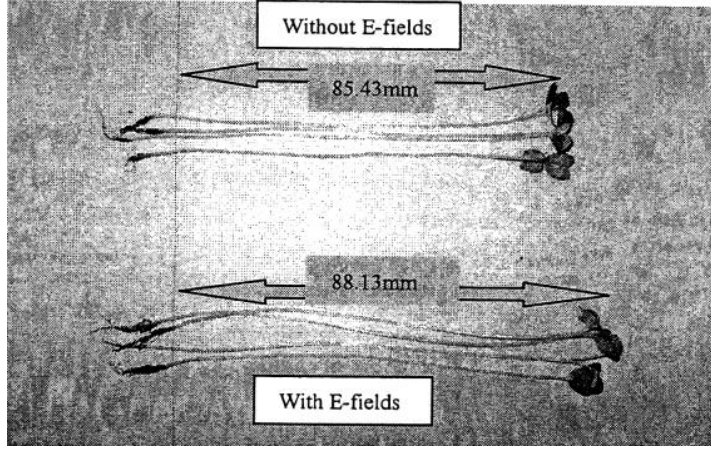

Figure 1. Comparison of the average height of 'Choy Sam' between with and without electric fields after two weeks

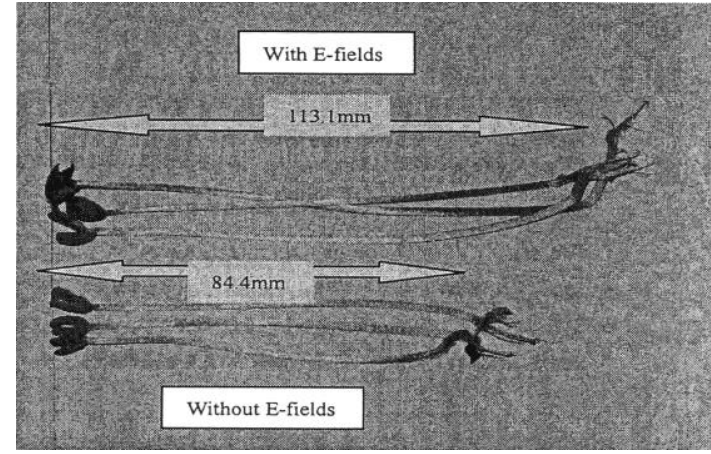

Figure 2. Comparison of the average height of bean sprouts between

with and without electric fields after one week

Figure 3 and Figure 4 show the comparison of the height of stem for 'Choy Sam' and bean sprouts between with and without electric fields treated water respectively. The heights of the stem for both young vegetables thatare watered with electric fields treated water were higher than those without electric fields treated water thereby elucidating the effect of electric field treated water towards the growth of the both young vegetables.

Figure 5 and Figure 6 show the percentage of germination for 'Choy Sam' and bean sprouts that exposed/did not expose to electric fields respectively. For Figure 5 on the day 2, the percentage of germination with electric fields was $20 \%$ more than without electric fields. From day 5 to day 14, the percentages of germination with/without electric fields were $76 \%$ and $74 \%$ respectively. For Figure 6 on the day two the percentage of germination with electric fields was $17.5 \%$ more than without electric fields. From the day 3 to day 6 , the percentages of germination with/without electric fields were $95 \%$ and $90 \%$ respectively.

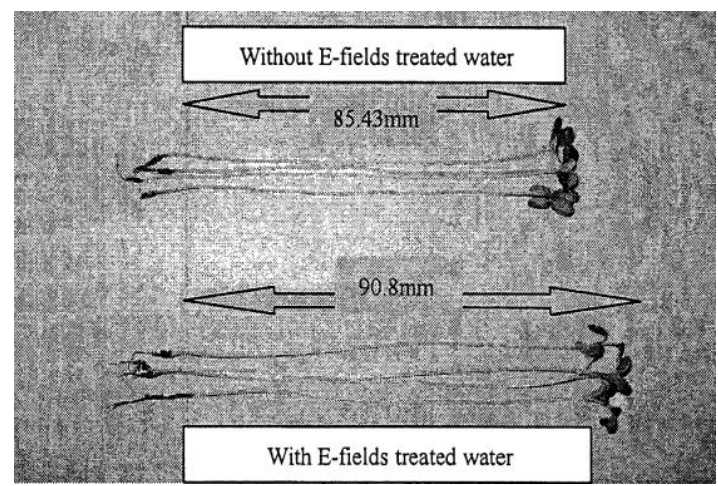

Figure 3. Comparison of the average height of 'Choy Sam' between with and without electric fields treated water after two weeks

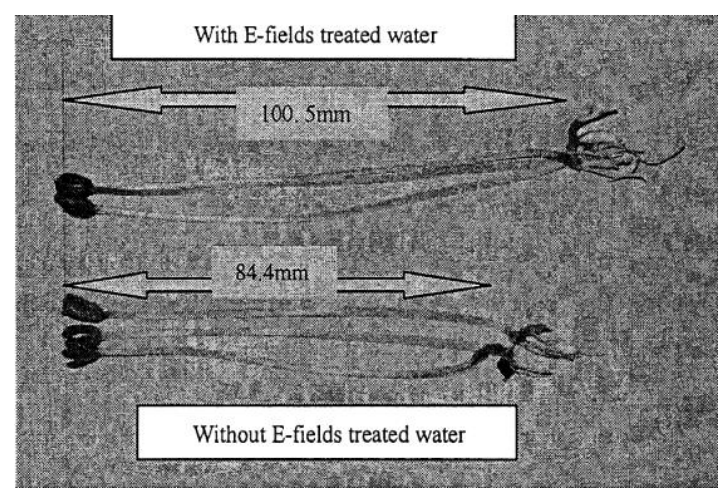

Figure 4. Comparison of the average height of bean sprouts between with and without electric fields treated water after one week 


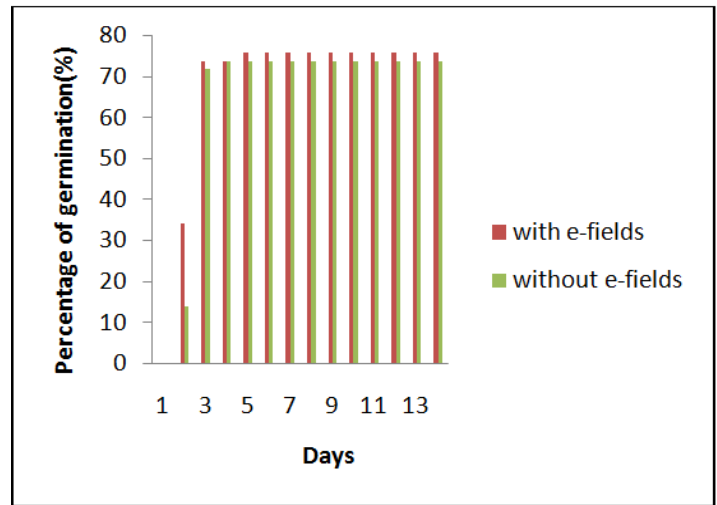

Figure 5. The germination rate vs. Days for 'Choy Sam' which exposed/do not expose to electric fields

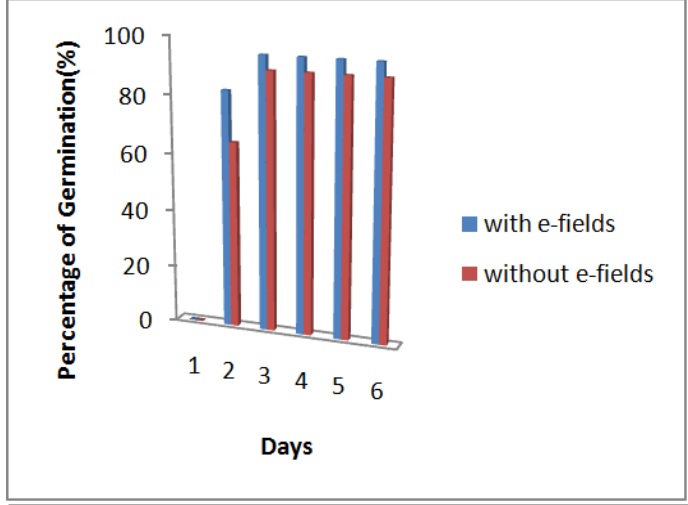

Figure 6. The germination rate vs. Days for near sprouts that exposed/do not expose to electric fields

Figure 7 and figure 8 show the arithmetic average height of stems and standard deviation for 'Choy Sam' and bean sprouts that exposed/do not expose to electric fields respectively. From the Figure 7 on the day 14, the average height was equal to $88.13 \mathrm{~mm}$ and the standard deviation was equal to $8.04 \mathrm{~mm}$ but without electric fields equal to $85.43 \mathrm{~mm}$ and $8.65 \mathrm{~mm}$ respectively. Besides that, the slope of the average height of stems for with and without electric fields was increased rapidly from day 1 to day 8 and increase gradually after day 8. The growing rates of 'Choy Sam' with and without electric fields have nearly the same rate of height for the first eight days. However, the growth of 'Choy Sam' with electric fields starts to increase from day 9 to day 14 . From Figure 8 , on the day 6 , the average height was equal to $113.10 \mathrm{~mm}$ and the standard deviation was equal to $25.24 \mathrm{~mm}$ but without electric fields was equal to $84.40 \mathrm{~mm}$ and $3.89 \mathrm{~mm}$ respectively.

Moreover, the slope of the average height of stems for with and without electric fields was increased steadily from day 1 to day 3 and increased speedily after three days but it was a maximum slope on the day 5 . The growing rates of bean sprouts with and without electric fields have nearly the same rate of height for the first three days. However, the growth of bean sprouts with electric fields starts to increase rapidly from day 4 to day 6.

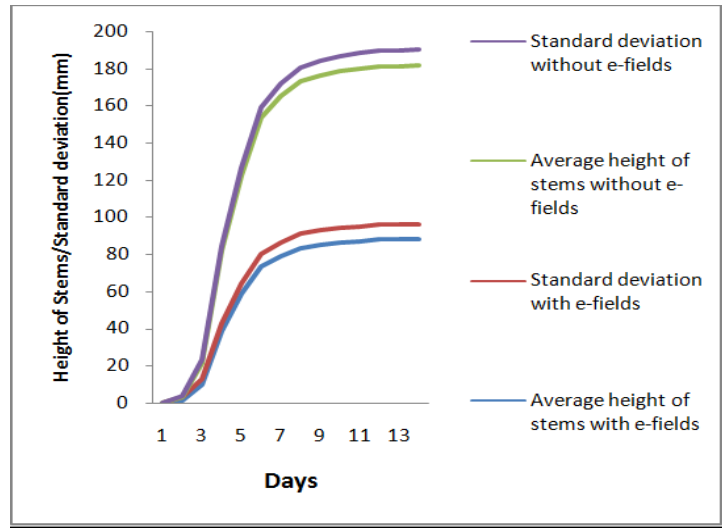

Figure 7. The height of stems and standard deviation vs. days for 'Choy Sam' which exposed/do not exposed to electric fields

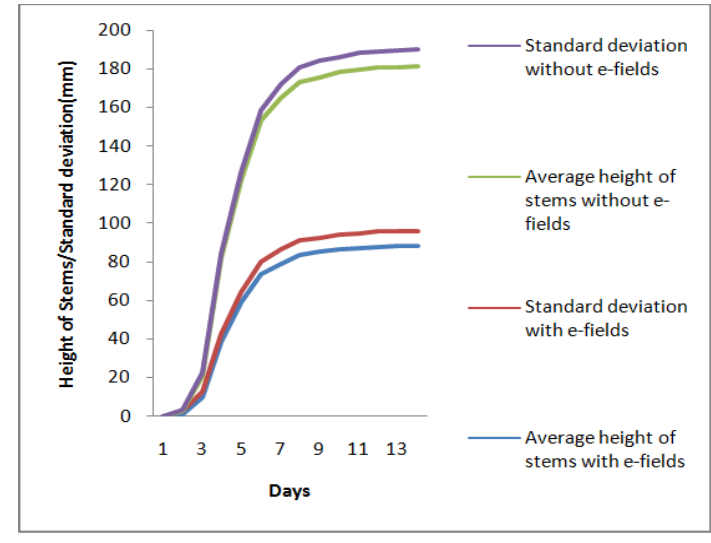

Figure 8. The height of stems and standard deviation vs. Days for bean sprout that exposed/do not expose to electric fields

Figure 9 and Figure 10 show the percentage of germination for 'Chow Sam' and bean sprouts that watered with/without electric fields treated water respectively. For Figure 9 on the 
day 2 , the percentage of germination with electric fields treated water was $2 \%$ more than without electric fields treated water. However, from day 4 to day 14, the percentages of germination without electric fields treated water are $4 \%$ more than with electric fields treated water. For Figure 10 on the day 2, the percentage of germination with electric fields treated water was $10 \%$ more than without electric fields treated water. From day 3 to day 6 , the percentages of germination with/without electric fields treated water were $92.5 \%$ and $90 \%$ respectively.

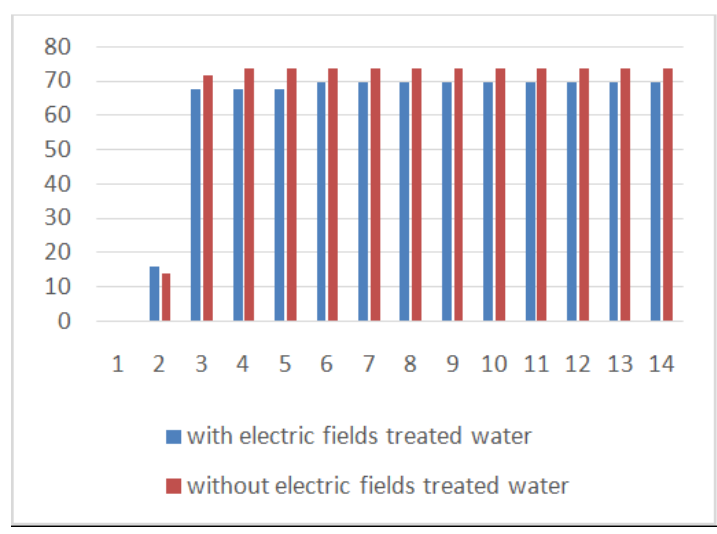

Figure 9. The germination rate vs. Days for 'Choy Sam' that watered with/without electric fields treated water

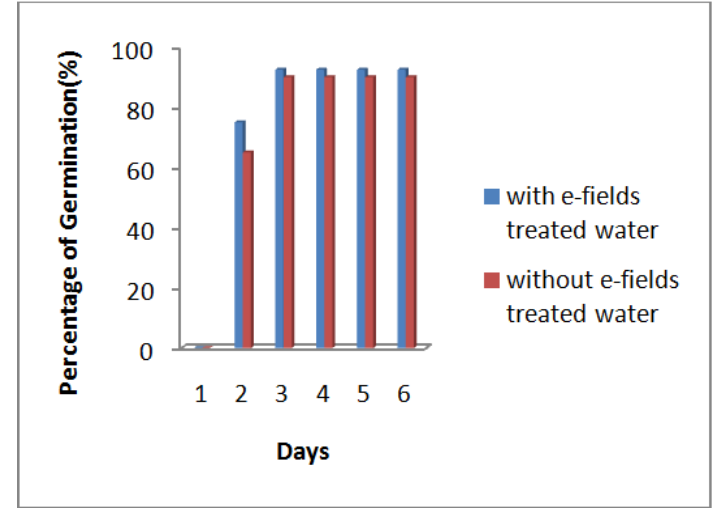

Figure 10. The germination rate vs. Days for bean sprouts that watered with/without electric fields treated water

Figure 11 and Figure 12 show the arithmetic average height of stems and standard deviation for 'Choy Sam' and bean sprouts that watered with and without electric fields treated water respectively. From the Figure 11, on the day 14, the average height was equal to 90.80 $\mathrm{mm}$ and the standard deviation was equal to $7.61 \mathrm{~mm}$ but without electric fields treated water was equal to $85.43 \mathrm{~mm}$ and $8.65 \mathrm{~mm}$ respectively. Furthermore, the slope of the average height of stems for with and without electric fields treated water was increased rapidly from day 1 to day 7 and increase gradually after day 7 . The growing rates of 'Choy Sam' with and without electric fields treated water have nearly the same rate of height for the first seven days. However, the growth of 'Choy Sam' with electric fields treated water starts to increase from day 8 to day 14 .

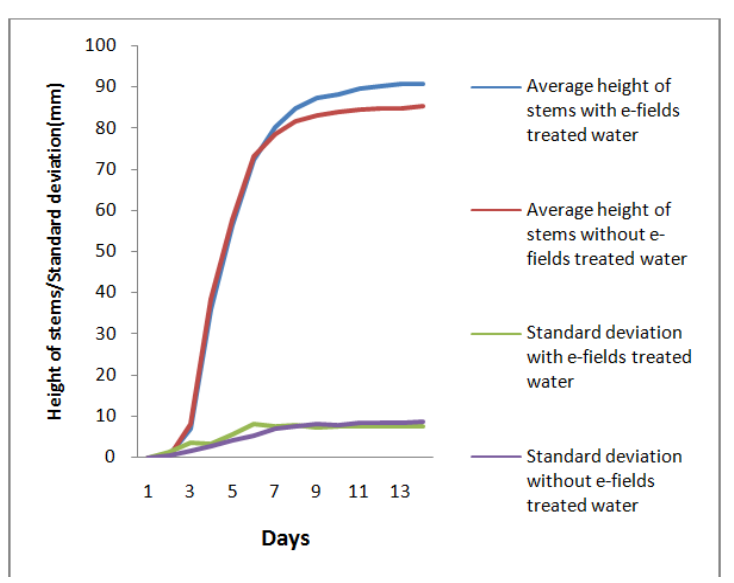

Figure 11. The height of stems and standard deviation vs. Days for 'Choy Sam' that watered with/without electric fields treated water

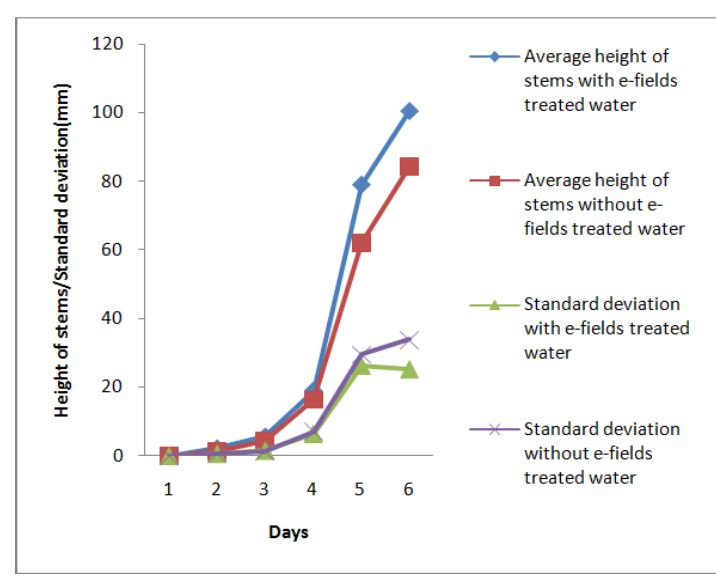

Figure 12. The height of stems and standard deviation vs. days for bean sprouts that watered with/without electric fields treated water 
From the Figure 12 on the day 6, the average height was equal to $100.50 \mathrm{~mm}$ and the standard deviation was equal to $25.12 \mathrm{~mm}$ but without electric fields treated water was equal $84.40 \mathrm{~mm}$ and $33.89 \mathrm{~mm}$ respectively. Apart from that, the slope of average height of stems for with and without electric fields treated water was increased gradually from day 1 to day 3 and increased rapidly after day 3 , but it was maximum slope on the day 5 . The growing rates of bean sprouts with and without electric fields treated water have nearly the same rate of height for the first four days. However, the growth of bean sprouts with electric fields treated water starts to increase speedily from day 5 to day 6 .

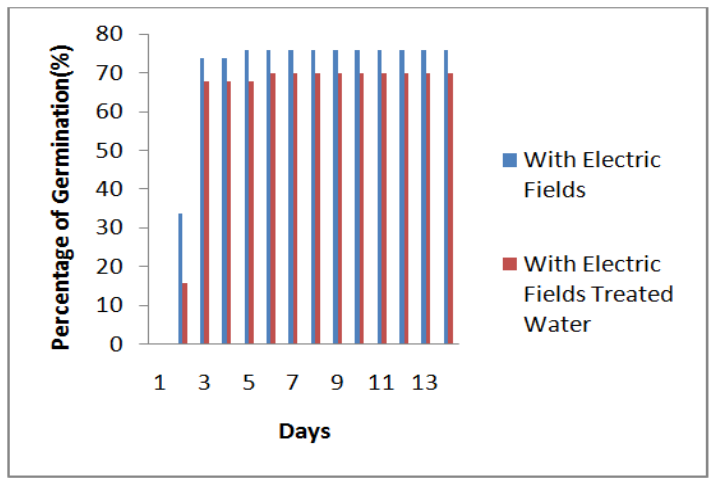

Figure 13. The germination rate vs. Days for 'Choy Sam' that exposed to electric fields and watered with electric fields treated water

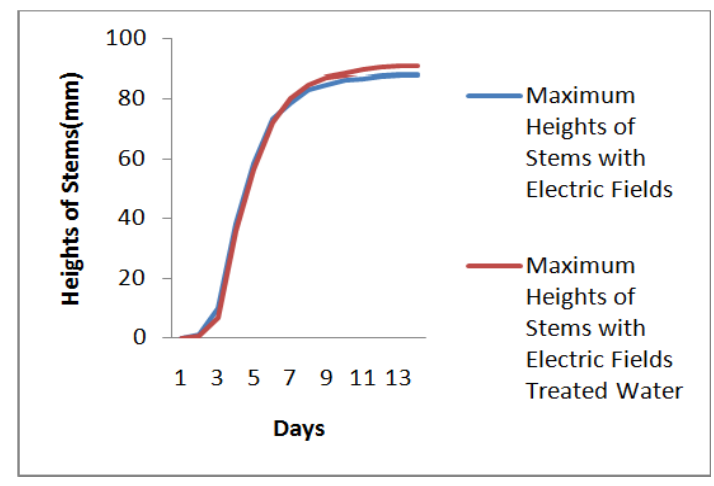

Figure 14. The height of stems vs. days for 'Choy Sam' which exposed to electric fields and watered with electric fields treated water

Figure 13 shows the percentage of germination for 'Choy Sam' which exposed to electric fields and watered with electric fields treated water respectively. On the day 2, the percentage of germination for 'Choy Sam' which exposed to electric fields was $18 \%$ more than those watered with electric fields treated water. However, from day 4 to day 14, the percentages of germination that exposed to electric fields were $6 \%$ more than with electric fields treated water. Figure 14 shows the comparison between the maximum heights of stems for 'Choy Sam' which exposed to electric fields and watered with electric fields treated water. From day two until day five, the maximum height of stems that exposed to electric fields was greater than the maximum height of stems that watered with electric fields treated water. However, the heights of these plants that watered with electric fields treated water were higher than those exposures with electric fields from day six until day 14. It means that that effect of electric fields treated water towards the growth of 'Choy Sam' was greater than the exposureto electric fields.

Figure 15 shows the percentage of germination for bean sprouts that exposed to electric fields and watered with electric fields treated water respectively. On the day 2 , the percentage of germination for bean sprouts that exposed to electric fields was $7.5 \%$ more than those watered with electrics fields treated water. However, from day 4 to day 14, the percentages of germination that exposed to electric fields were $2.5 \%$ more than with electric fields treated water.

Figure 16 shows the comparison between the maximum heights of stems for bean sprouts that exposed to electric fields and watered with electric fields treated water. From day two until day 6 , the maximum height of stems that exposed to electric fields was greater than the maximum height of stems that watered with electric fields treated water. On the day 6 , the maximum heights of stems that exposed with electric fields were $16 \mathrm{~mm}$ higher than those watered with electric fields treated water. It means that the effect of electric fields towards the growth of bean sprouts was greater than electric fields treated water. 


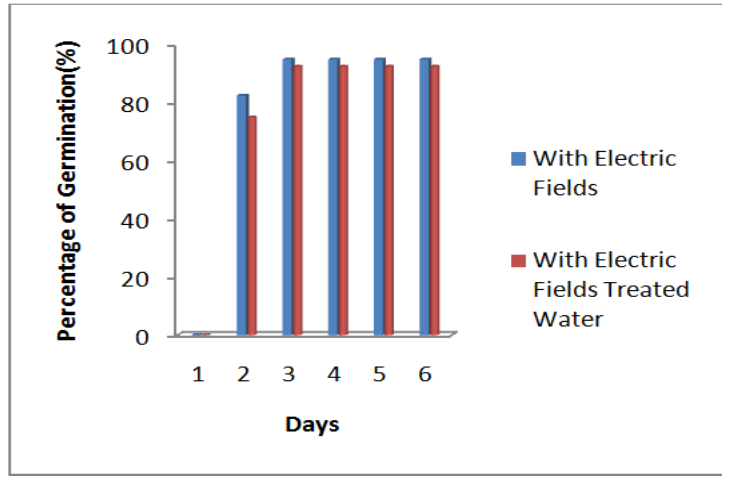

Figure 15. The germination rate vs. Days for bean sprouts that exposed to electric fields and watered with electric fields treated water

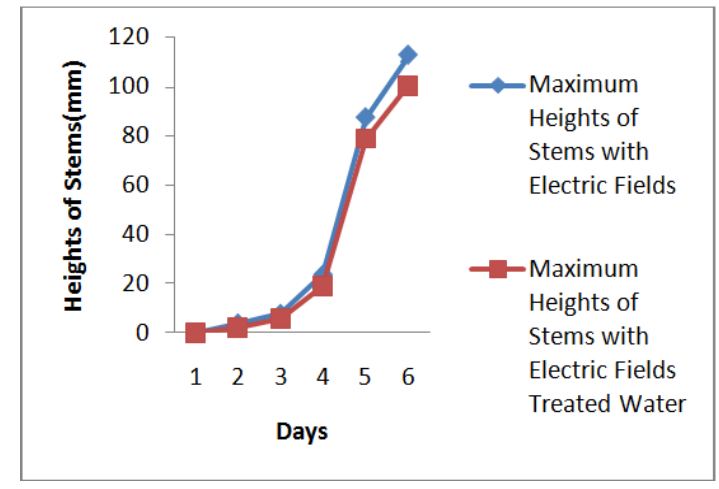

Figure 16. The height of stems vs. Days for bean sprouts that exposed to electric fields and watered with electric fields treated water

\section{Conclusion}

The percentage of germination and growth rate for both young vegetables has been considered in the experiment based on the statistical approach. This give more quantitative analysis of the effect of electric fields on the germination and growth rate of young vegetables. From these results, electric fields and electric fields treated water influenced the germination rate and height of stems for both young vegetables. The height of stems in with electric fields and electric fields treated water are higher and longer than of those without electric fields and electric fields treated water. Last but not least, it is clear that vast track of land along the transmission lines right-of-way is not utilized for the useful purpose. This is because of the hazardous of electric and magnetic fields towards humans. Based on the regulation made by the government, the land located nearby the transmission cannot be built in a residential suburb. As a result, this experiment leads to the possibility of cultivates vegetables in those places. From the positive results as shown in this research concerted and organized farming of vegetable utilizing power lines right-of-way should be undertaken.

\section{References}

[1] Kiatgamjorn P, W Khan-ngern, S Nitta. Electric Field Direction Effects on the Growth of Bean Sprouts. Young 50: $3 \mathrm{~mA}$.

[2] Kiatgamjorn P, W Khan-ngern, S Nitta. The effect of electric field on bean sprout growing. In 2002 International Conference on Electromagnetic Compatibility (ICEMC2002). Bangkok, Thailand. 2002: 237-241.

[3] Sheikh, Faizan Ahmed, Raminder Preet Pal Singh, Parveen Lehana. Effect of High Voltage on the Resistance of Aloe Vera Leaves.

[4] Wheaton, Fredrick Warner. Effects of various electrical fields on seed germination.1968.

[5] Mahajan TS, OP Pandey. Effect of electric field (at different temperatures) on germination of chickpea seed. African Journal of Biotechnology. 2015; 13(1).

[6] MS Naidu, V Kamaraju. High Voltage Engineering. Third Edition. The McGraw-Hill Publishing Company Limited. 2004.

[7] Zalina Mohd Daud, Maizah Hura Ahmad, Robiah Adnan, Sharifah Suhaila Syed Jamaluddin, Fadhilah Yusof, Ismail Mohamad. Statistics Workbook for Sciences and Engineering. First Edition. Jasamax. 2004.

[8] Donna H Skane. Elementary Statistics. Addison-Wesley Publishing Company, Inc. 1985. 